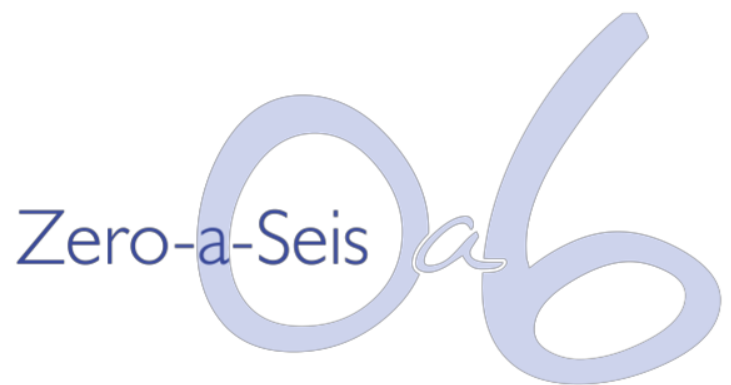

\title{
PROFISSIONALIDADE E GÊNERO: PARTICIPAÇÃO DOS HOMENS E PEQUENA INFÂNCIA ${ }^{1}$ \\ Professionalité et genre: participation des hommes et petite enfance \\ Professionality and gender: men's participation and early childhood
}

\author{
Tradução por Ângela Scalabrin COUTINHO \\ Doutora em Estudos da Criança \\ Universidade Federal do Paraná \\ Departamento de Teoria e Prática de Ensino \\ Curitiba, Brasil \\ angelamscoutinho@gmail.com \\ https://orcid.org/0000-0002-3709-8561 ()
}

\author{
Jan PEeTERS \\ Doutor em Educação \\ Universidade de Gante \\ Departamento de Pedagogia Social e Trabalho \\ Social \\ Gante, Bélgica \\ Jan.Peeters@UGent.be \\ https://orcid.org/0000-0002-2164-7562 (0)
}

A lista completa com informações dos autores está no final do artigo

\begin{abstract}
PREÂMBULO
A abordagem da relação entre profissionalidade e gênero no trabalho com a pequena infância, proposta neste artigo, exige uma breve contextualização. Jan Peeters é diretor do Centro de Inovação da Pequena Infância, um centro de pesquisa ligado à Universidade de Gante, na Bélgica, e ao curso de Pedagogia Social e Trabalho Social. Seus estudos se centram na relação entre gênero e pequena infância, com destaque à coordenação de cinco projetos sobre a profissionalização dos serviços para a pequena infância, no âmbito da União Europeia (UE). Os serviços para a pequena infância no âmbito da UE, em especial nos países e regiões citados por Peeters no artigo, são variados e, de modo geral, possuem caráter intersetorial, envolvendo áreas como assistência social, educação e saúde. Ainda que em diferentes países - mesmo regiões e cidades - possuam características próprias, pode-se caracterizá-los como serviços que surgem com uma perspectiva de guarda e mais recentemente incorporam uma perspectiva de acolhimento. 0 acolhimento é, deste modo, uma concepção mais alargada sobre o compartilhamento com as famílias da educação e cuidado das crianças pequenas, que pode ocorrer em instituições coletivas, instituições de pequeno porte que acolhem poucas crianças, em alguns contextos até cinco, no espaço privado da família, com a contratação de um/a profissional credenciado/a pelo órgão responsável, dentre outras formas. Essa variedade de serviços, nomeada em algumas passagens do texto como estruturas para a pequena infância, se difere significativamente do contexto brasileiro, e exige alguma atenção para a sua compreensão, inclusive em relação às terminologias utilizadas, como acolhimento, quando refere ao objetivo dos serviços e cuidadores/as e educadores/as, quando identifica os/as profissionais que atuam nos diferentes serviços com as crianças. Em relação ao tema central - a relação entre gênero e profissionalidade - 0 autor trata-o considerando o conjunto de profissionais que atuam nos diferentes serviços de acolhimento das crianças pequenas. Os estudos, políticas e programas que descreve e analisa ao longo do texto levam-no a defender uma equidade de gênero nas profissões da pequena infância, o que o autor denomina de profissionalidade neutra no plano do gênero, definição proveniente em especial das experiências desenvolvidas no Reino Unido no Sheffield Children's Centre e no Pen Green Family Centre, serviços integrados para a pequena infância, que desde os anos 1980 empregam quase tantos homens como mulheres. Estes breves apontamentos buscam situar aspectos que caracterizam a importante contribuição de Jan Peeters ao debate
\end{abstract}

\footnotetext{
${ }^{1}$ Este capítulo baseia-se em uma comunicação feita em 2009 nas Segundas Jornadas da Pequena Infância da rede Idéal.
} 
sobre gênero e profissionalidade no trabalho com a pequena infância e introduzir o/a leitor/a na abordagem aqui apresentada, que foi sistematizada a partir de uma conferência realizada em 2009, transformada em artigo e publicada em 2013, na obra "Pequena infância e participação: uma abordagem democrática do acolhimento" (Petite enfance et participation: une approche démocratique de l'accueil), organizada por Sylvie Rayna e Catherine Bouve.

PALAVRAS-CHAVE: Profissionalidade. Gênero. Homens. Pequena Infância.

\section{PREAMBLE}

The approach of the relationship between professionalism and gender at work with early childhood, proposed in this paper, requires a brief contextualization. Jan Peeters is director of the Centre for Innovation in the Early Years, a research center linked to the University of Gante in Belgium and the Social Pedagogy and Social Work course. His studies focus on the relationship between gender and early childhood, with emphasis on the coordination of five projects on the professionalization of services for early childhood, within the Framework of the European Union (EU). Early-childhood services within the EU, especially in countries and regions cited by Peeters in this article, are varied and generally intersectoral in nature, involving areas such as social assistance, education and health. Although in different countries - even regions and cities - they have their own characteristics, they can be characterized as services that arise with a perspective of custody and more recently incorporate a perspective of reception. Therefore, welcoming is a broader conception about the sharing with the families of education and care of young children, which can occur in collective institutions, small institutions that welcome few children, in some contexts up to five, in private space of the family, with the hiring of a professional accredited by the responsible body, among other forms. This variety of services, named in some passages of the text as structures for early childhood, differs significantly from the Brazilian context, and requires some attention to their understanding, including in relation to the terminologies used, as welcoming, when referring to the objective of the services and caregivers and educators, when it identifies the professionals who work in different services with the children. In relation to the central theme - the relationship between gender and professionalism - the author treats it considering the set of professionals who work in different care services of young children. The studies, policies and programs that he describes and analyses throughout the text lead him to advocate gender equity in professions of young childhood, which the author calls gender-neutral professionalism, a definition derived in particular from the experiences developed in UK at Sheffield Children's Center and the Pen Green Family Center, integrated services for small childhood, which since the 1980 s employ almost as many men as women. These brief notes seek to situate aspects that characterize the important contribution of Jan Peeters to the debate on gender and professionalism at work with early childhood and introduce the reader in approach presented here, which was systematized from a conference held in 2009, transformed into a paper and published in 2013, in "Little Childhood and Participation: a Democratic Approach to Welcoming" (Petite enface et participation: une approche démocratique de l'accueil), organized by Sylvie Rayna and Catherine Bouve.

KEYWORDS: Professionalism. Gender. Men. Early Childhood. 


\title{
A ReLAÇÃo entre PROFissionalidade e GÊNERO NAS PROFISSÕES DA PEQUENA INFÂNCIA
}

Claire Cameron estudou a relação entre profissionalização das profissões da pequena infância e participação dos homens. Ela partiu da constatação da tendência para a profissionalização na maioria dos países europeus:

\begin{abstract}
Na Inglaterra, esta evolução manifesta-se, por um lado em nível político, tendo como objetivo o futuro social e educativo das crianças e uma melhor disponibilidade e acessibilidade dos serviços para a pequena infância, entre outros, e, por outro lado, em nível setorial, com uma maior identificação graças à noção de ser um "profissional" (CAMERON, 2006, p. 69).
\end{abstract}

Em alguns países, a tendência à profissionalização manifesta-se mais através do desenvolvimento de um modelo de profissionalidade segundo o qual existe apenas um tipo de profissional, com um nível de qualificação elevado (graduação ${ }^{2}$ ou mestrado). É o caso da Dinamarca, da Suécia e da Nova Zelândia, para todas as estruturas destinadas às crianças entre 0 e 5 anos (PEETERS, 2008, 2010), e da Bélgica e da França, para a escola maternal. Claire Cameron afirma que, nesses países,

[...] uma profissionalização, em termos de formação longa, de corpo único de conhecimentos e de identidade profissional distinta, foi alcançada com uma força de trabalho quase inteiramente feminina e anterior aos esforços feitos para recrutar mais homens. (CAMERON, 2006, p. 71).

Assim, é necessário acreditar que um nível de profissionalidade elevado não conduz automaticamente a um aumento do número de profissionais homens. Um processo de profissionalização não está necessariamente ligado ao aumento do número de homens que trabalham nos serviços para a pequena infância: ambos os processos podem claramente manifestar-se independentemente um do outro (CAMERON, 2006, p. 76). Um ótimo exemplo é o da Nova Zelândia, onde todos os que trabalham com crianças entre 0 e 6 anos deveriam, até 2012, obter um diploma de graduação: os homens representam apenas $1 \%$ das equipes (FARQUHAR et al., 2006).

Por outro lado, há países onde parece ser possível atrair mais homens e isso é possível sem que um nível de profissionalização muito elevado seja exigido. Na Escócia, onde $40 \%$ dos profissionais que trabalham no contexto da pequena infância não

\footnotetext{
2 Nota da tradutora: no original, licence corresponde ao primeiro ciclo do Ensino Superior, antes do mestrado, segundo ciclo, e do doutorado, terceiro ciclo. Tem duração de 3 anos após o baccalauréat ou um de seus equivalentes.
} 
atingem o nível 2 do Quadro Europeu de Certificações ${ }^{3}$ (MILLER, 2006, p. 3), excelentes resultados foram, no entanto, alcançados em termos de atratividade de profissionais do sexo masculino. Neste país, o projeto "Men in Childcare" ("Homens na Educação infantil") conseguiu motivar 900 homens a buscarem um tipo de formação (frequentemente pouco qualificada) (SPENCE, 2007).

\section{UMA CONSTRUÇÃO FEMININA DA PROFISSIONALIDADE}

Existe efetivamente uma relação entre a profissionalidade das profissões da pequena infância e o atrativo dessas profissões para os homens. Os homens, na verdade, só são atraídos por funções de acolhimento-educação de crianças pequenas na condição de que essas funções não serão baseadas numa profissionalidade ligada ao gênero, em outras palavras, ao papel de mãe (PEETERS, 2005; CAMERON, MOSS, OWEN, 1999). Claire Cameron afirma, com base em um estudo realizado junto a profissionais do sexo masculino, que uma profissionalidade baseada em uma "prática do tipo maternal" constitui um obstáculo ao acesso dos homens a esta esfera. Ela fala de "retirar o modelo, ligado ao gênero, desta profissão" (CAMERON, 2006, p. 76).

Parece oportuno redefinir a identidade profissional e o estatuto das profissões da pequena infância. O estudo dos aspectos relacionados ao gênero das profissões ligadas às crianças pequenas, pode, na verdade, contribuir para o "profissionalismo democrático", tal como Pamela Oberrhuemer definiu:

[...] o profissionalismo democrático pressupõe a compreensão de várias formas de saber e a noção que o conhecimento é de fato contestável. Isto implica uma vontade e uma capacidade de refletir sobre as suas próprias evidências. (OBERHUEMER, 2005, p. 14).

Claire Cameron defende que as experiências dos profissionais do sexo masculino podem alargar o conhecimento da profissão.

Ao questionar constantemente os aspectos especificamente ligados ao gênero, na tradição do "prático reflexivo" (SCHÖN, 1983-1994), é possível redefinir as profissões da pequena infância.

Embora o profissionalismo e o acesso dos homens a essas profissões não estejam necessariamente ligados, o tipo de profissionalismo continua a ser importante: uma

\footnotetext{
3 Nota da tradutora: o Quadro Europeu de Certificação foi adotado por recomendação do Parlamento Europeu e do Conselho da União Europeia, estabelecendo certificações para a educação e a formação ao longo da vida. O Quadro é uma ferramenta criada para favorecer a comparação de formações e de diplomas.
} 
definição especificamente ligada ao gênero da profissionalidade limitará o acesso dos homens à profissão, enquanto uma construção da profissionalidade neutra, do ponto de vista do gênero, poderia encorajar a sua participação.

Na próxima seção, vamos analisar a evolução da reflexão quanto à uma profissionalidade neutra, no plano do gênero, e desenvolver a tese segundo a qual uma definição neutra, no plano do gênero, é necessária para tornar a profissão mais atrativa para os homens.

\section{A INFLUÊNCIA DA REDE EUROPEIA DE ACOLHIMENTO Às CRIANÇAS}

Em 1982, a União Europeia lançou o primeiro programa a favor da igualdade entre homens e mulheres (Gender Equality Program), com a intenção de oferecer às mulheres oportunidades iguais no mercado de trabalho. É neste contexto que a Rede Europeia de Acolhimento de Crianças foi criada em 1986 e dirigida por Peter Moss, professor na Universidade de Londres. Um dos três pontos de ação dessa rede era o tema "Os homens como cuidadores de crianças". No que diz respeito à igualdade dos gêneros, os homens deveriam aumentar o número de tarefas domésticas e seriam assim mais envolvidos na educação de crianças pequenas.

Este tema foi igualmente evocado nas recomendações sobre o acolhimento das crianças pequenas, do Conselho de Ministros da UE (CONSELHO DA COMUNIDADE EUROPEIA, 1992): "Os Estados-membros se comprometem em promover e encorajar, respeitando a liberdade do indivíduo, um aumento da participação masculina (artigo 6)".

Em 1993, a Rede de Acolhimento de Crianças, convidou especialistas dos diferentes Estados-membros europeus, em Ravenna, para debaterem os homens como cuidadores de crianças. Os especialistas concordaram que, se mais educadores homens não fossem recrutados, as medidas destinadas a envolver mais os homens na educação das crianças pequenas teriam pouca influência (EC CHILDCARE NETWORK, 1993). Os profissionais do sexo masculino poderiam servir de modelo para os jovens pais. Ao mesmo tempo, os serviços da pequena infância poderiam desempenhar um papel importante no desenvolvimento de uma nova cultura de cuidado das crianças: uma cultura que convide também os homens. Outro argumento importante evocado para empregar mais homens nas estruturas para a pequena infância partia do princípio de que as crianças seriam assim confrontadas com modelos masculinos. Segundo a Rede, 
esta situação teria uma influência sobre as futuras gerações que repartiriam melhor as tarefas domésticas e parentais entre homens e mulheres.

No entanto, os especialistas constataram que existia, na UE, um número limitado de serviços no âmbito da pequena infância em que os homens constituíam uma parte significativa do pessoal. Na maioria dos países europeus, os homens representam 1 a $3 \%$, apenas. É por isso que a Rede de Acolhimento decidiu que devem ser feitos esforços sérios para elevar a participação masculina nestes serviços. No início dos anos 1990, os países escandinavos lançaram várias iniciativas e campanhas para aumentar o número de homens nos serviços destinados às crianças com menos de 6 anos. Na Dinamarca, o tema figurava na agenda política. Os resultados obtidos são os seguintes: $5 \%$ de profissionais homens nas creches ( 0 a 3 anos), 9\% nos jardins de infância ( 3 a 6 anos) e nas instituições que acolhem crianças de idades mistas ( 0 a 12 anos) e 25\% nos serviços extraescolares. Desde os anos 80, no Reino Unido, dois serviços integrados da pequena infância, o Sheffield Children's Centre (MELEADY, BROADHEAD, 2002) e o Pen Green Family Centre, empregaram quase tantos homens como mulheres. Desde o início dos anos 90, estes dois centros desenvolveram um novo tipo de profissionalidade, discutindo abertamente as diferenças de gênero. Além disso, foi elaborada uma definição de profissionalidade neutra no plano do gênero (CAMERON, MOSS, OWEN, 1999; MELEADY, BROADHEAD, 2002).

Os educadores destes dois centros, os pesquisadores e os responsáveis políticos da Emilia Romagna (Itália), da Noruega, da Suíça e da Dinamarca, constituíram um grupo pioneiro que cooperou estreitamente com a Rede (JENSEN, 1998, p. 128).

Neste interim, a Rede publicou o documento de discussão "Qualidade dos serviços da pequena infância", que foi traduzido para todas as línguas dos então doze Estadosmembros da União Europeia. O tema dos profissionais homens era uma das temáticas dessa publicação que, de resto, deu lugar a uma discussão nos Estados-membros entre investigadores, responsáveis políticos e representantes de educadores de crianças pequenas.

Em 1995, a Rede de Acolhimento de Crianças da Comissão Europeia publicou o relatório "Quarenta objetivos qualitativos dos serviços de pequena infância", no qual as discussões realizadas no âmbito da UE-12 foram resumidas em quarenta objetivos qualitativos, aplicáveis pelos Estados-membros durante um período de dez anos. 0 objetivo no 29 deste documento, estipulava que $20 \%$ dos profissionais de acolhimento deveriam ser homens. 
A Rede, cujas atividades terminaram em 1996, teve, sem dúvida, a tarefa de chamar a atenção para o tema do gênero e de colocá-lo na agenda dos Estadosmembros da União Europeia.

Graças à influência dessa rede, foi disponibilizado um financiamento europeu para empreender ações destinadas a tornar as profissões envolvendo a pequena infância, na Europa, mais atrativas para os homens. O Fundo Social Europeu financiou, nomeadamente, inúmeros projetos em diferentes países europeus, a fim de assegurar o equilíbrio entre homens e mulheres nas estruturas para a pequena infância, à procura da construção de uma profissionalidade neutra no que diz respeito ao gênero nas profissões relacionadas com crianças pequenas.

A União Europeia e a OCDE mostraram um novo interesse pela questão do gênero, mas, desta vez, mais por razões econômicas (EUROPEAN COMISSION, 2006; OCDE, 2006). A Comissão e a OCDE constataram, com efeito, um envelhecimento geral da população em todos os países membros. Do mesmo modo, as empresas europeias teriam que encontrar uma solução para a inevitável crise no setor de cuidados. A demanda no mercado de trabalho por profissionais deste setor vai, de fato, aumentar. Além disso, as mulheres que entram no mercado de trabalho possuem qualificações mais elevadas do que as pessoas que o deixam e estarão menos interessadas nas profissões deste setor.

Em outras palavras, é necessário encorajar os homens a substituir as mulheres nas profissões do setor de cuidados. Essa é, aliás, uma das razões pelas quais a Europa se interessa muito pela questão de gênero. Na verdade, receia-se que dentro de dez a quinze anos não haja pessoas suficientes para ocupar as profissões deste setor, o da pequena infância, mas também o das pessoas idosas (CAMERON; MOSS, 2007).

A Europa quer criar não só mais empregos para as mulheres, mas também melhores empregos no âmbito da pequena infância. Deste modo, a qualidade do emprego torna-se um objetivo central da UE, empenhada em basear a economia no conhecimento.

\section{AS CAusas da segregaÇÃo de GÊnero nOS SERVIÇOS PARA A PEQUENA INFÂNCIA}

Na sequência do pedido da Rede de Acolhimento de Crianças da Comissão Europeia, Fred Deven, membro da Rede, realizou, em 1995, um levantamento sobre o 
número de homens ativos no setor da pequena infância em Flandres (PETEERS, 2002). Entre as 14.560 pessoas que trabalhavam nas creches flamengas ( 0 a 3 anos), havia no total 81 homens, ou seja, 0,55\% ou, ainda, um homem para 200 mulheres. Fred Deven distinguiu o acolhimento coletivo, onde havia 1,5\% de homens e o acolhimento familiar, que parecia ser um contexto quase exclusivamente feminino $(0,1 \%$ de homens). Na Dinamarca, os números eram ligeiramente mais positivos, com $5 \%$ de homens junto às crianças com menos de 3 anos. A cidade de Barcelona estava em um bom caminho com 4\%. Na Suécia, havia 3\% de homens nas estruturas de acolhimento de crianças com menos de 6 anos, e a Finlândia tinha 4\%. No Reino Unido, a pequena infância era a esfera profissional que mais segregava quanto ao gênero, com apenas $2 \%$ de homens nas estruturas frequentadas por crianças com menos de 6 anos (JENSEN, 1998).

Podemos afirmar que as funções no acolhimento da pequena infância e na escola maternal são verdadeiramente femininas. Nos últimos anos, muitos tentaram encontrar uma resposta para a questão de por que razão tão poucos homens participam na esfera da pequena infância. As razões são apresentadas a seguir.

\section{A RELAÇÃO HISTÓRICA COM O MOVIMENTO FEMINISTA}

Em todas as profissões relacionadas com crianças, as mulheres constituem a maioria. Além disso, o grau de segregação de gênero relaciona-se à idade das crianças: quanto mais jovens forem as crianças, mais mulheres haverá (MOSS, 2003). Ainda, o cuidado às crianças é desde sempre um tema importante do movimento feminista (DESMET et al., 1978; POT, 1981; BORCHORST, 2006; FARQUHAR et al., 2006). "Os serviços para a pequena infância sempre foram promovidos, utilizados e ocupados por mulheres" (FARQUHAR et al., 2006, p. 3). Em muitos países industrializados, o movimento de emancipação feminina tem um impacto significativo no aumento da profissionalidade nos contextos da pequena infância e no aumento dos salários.

O acolhimento à pequena infância conheceu, até finais de 1980, um vínculo estreito com o movimento feminista que, por um lado, queria, através de mais espaço junto à pequena infância, oferecer às mulheres a oportunidade de trabalharem fora de casa, e, por outro, empregar mulheres neste setor (FARQUHAR et al. 2006). De acordo com Sarah Farquhar, essa ligação com o movimento feminista é uma das razões pelas quais há tão poucos homens que se orientam para os espaços da pequena infância. 


\section{UMA PROFISSÃO FEMININA NÃO É ATRATIVA PARA OS HOMENS}

As mulheres sentem-se atraídas por profissões masculinas porque essas têm muito a oferecer: mais prestígio, melhores salários e maiores oportunidades de carreira, enquanto os homens que escolhem as profissões femininas tradicionais têm menos a ganhar e, muitas vezes, têm de contentar-se com um salário menos elevado e de menor prestígio. "Os homens com funções não tradicionais têm menos a ganhar e muito a perder: um sacrifício no que diz respeito ao salário e ao prestígio; além disso, estão susceptíveis a questões sobre a sua masculinidade e a sua capacidade profissional" (SIMPSON, 2005, p. 364). Um estudo realizado em Luxemburgo concluiu: "O primeiro fator salientado é a falta de valorização, tanto financeira como ligada à complexidade da tarefa e às exigências do público" (SCHANDELER, 2010, p. 128).

Sarah Farquhar propõe ainda outro elemento que impediria os homens de optarem por uma profissão relacionada às crianças: "Os homens ativos no acolhimento remunerado são muitas vezes considerados como se não fossem "homens verdadeiros" ou como "homossexuais" (FARQUHAR et al. 2006, p. 6). A relação entre a homossexualidade e a escolha de uma profissão em um contexto da pequena infância ainda não foi analisada. Um outro estudo desta situação para outras profissões tipicamente femininas demonstra que os homossexuais masculinos têm menos dificuldades em se manifestar em profissões tipicamente femininas e que têm menos problemas de identidade do que os homens heterossexuais quando trabalham em um ambiente predominantemente feminino (SIMPSON, 2005).

O salário e o ambiente de trabalho são importantes, mas não constituem o elemento principal. Nos países em que o nível de profissionalização é elevado, como na Nova Zelândia, na Suécia e também no que diz respeito à escola maternal flamenga, onde os salários são idênticos aos da escola primária e secundária, notamos, no entanto, que poucos homens são empregados (FARQUHAR et al., 2006; CAMERON, 2006).

\section{O MEDO DE SER ACUSADO DE PEDOFILIA}

O medo do abuso sexual ocupa um lugar importante, especialmente nos países anglo-saxônicos (ROLFE, 2005). "As mulheres que trabalham no setor da pequena 
infância são consideradas seguras, mas os homens são objeto de suspeitas" (FARQUHAR et al., 2006, p. 6). O receio de serem acusados de abuso sexual impediu os homens, especialmente na Nova Zelândia, de escolherem uma profissão relacionada com crianças. Sarah Farquhar estabelece a ligação entre os escândalos de pedofilia e a ausência de homens nestas profissões. Na Nova Zelândia, o número de homens passou de $2 \%$ para $1 \%$, depois de um incidente de abuso sexual ter sido amplamente noticiado na imprensa sensacionalista nos anos 1990 (FARQUHAR et al., 2006). Um estudo realizado pelo Day Care Trust no Reino Unido revelou que, para $57 \%$ dos adultos interrogados, o risco de pedofilia constituía uma barreira ao recrutamento de homens no setor da pequena infância (ROLFE, 2005). Na Dinamarca, mas também na região de Flandres, existe muito menos receio de ser injustamente acusado de abuso sexual (JENSEN, 1998; PEETERS, 2003). No entanto, os recentes escândalos nos Países Baixos demonstraram que os homens que trabalham com crianças pequenas se sentiriam ameaçados se um escândalo de pedofilia fosse desencadeado (DE STANDAART, 14 de dezembro de 2010).

\section{A esfera de ACOLHIMENTO dA PEQUena INfÂNCIA PERCEBIDA COMO UMA PROFISSÃO FEMININA}

Segundo alguns autores, a causa principal do número elevado de mulheres nas profissões relacionadas às crianças pequenas reside no fato de a esfera da pequena infância ser entendida como um "trabalho feminino" (CAMERON, MOSS E OWEN, 1999; CAMERON, 2001; FAQUHAR et al., 2006). Este setor é concebido como substituto ao papel da mãe. Claire Cameron, Peter Moss e Charlie Owen utilizam o conceito de "gênero": as diferentes particularidades e aptidões atribuídas por uma cultura aos homens ou às mulheres. O gênero distingue-se do sexo que se relaciona unicamente com as diferenças biológicas entre homens e mulheres. Segundo Mieke Dejonckheere e Katlijn Demuyinck:

Gênero e sexo estão estreitamente ligados entre si, dado que o sexo, determinado biologicamente, determinará o gênero (masculino ou feminino) que a sociedade espera. Tendo em vista que se trata de uma construção social, o gênero está fortemente sujeito a mudanças: as diferenças entre homens e mulheres variam em função do lugar, da cultura, da etnia e da classe. (apud PEETERS, 2002, s/p).

Segundo o estudo de Cameron, Moss e Owen (1999), o gênero participaria de forma inconsciente na construção da profissionalidade das tarefas relacionadas com as 
crianças. Cuidar de crianças - com ou sem remuneração - é visto como uma ocupação feminina. Uma coisa que as mulheres fazem naturalmente (melhor). Este mecanismo de gênero funciona em dois níveis.

No nível individual, os educadores trazem as suas opiniões específicas, através das suas próprias identidades de gênero, sobre a definição da profissionalidade nos contextos da pequena infância: o papel, as tarefas e os modos de ser tanto dos homens como das mulheres em um contexto específico da profissão nesta esfera. Neste contexto, Carmen Dalli realizou um estudo sobre a forma como os profissionais da pequena infância, que acabaram recentemente os seus estudos, construíam a sua identidade profissional. "Os dados do estudo mostram que vários aspectos do discurso dos professores sobre o seu trabalho alinhavam a sua função profissional com a das mães" (DALLI, 2002, p. 82).

O gênero desempenha igualmente um papel no nível institucional: mostra o seu impacto na história da origem do setor da pequena infância e na forma como esse setor é organizado (profissionalidade da organização). Assim, o aspecto relacionado ao gênero determinou, em parte, a política dos poderes públicos e a prática pedagógica deste setor (profissionalidade das atividades). O acolhimento da pequena infância desenvolveu-se através de um certo tipo de cuidados prestados às crianças, ou seja, os cuidados maternos. Segundo vários autores, esta é a principal causa da participação limitada dos homens no trabalho com a pequena infância (CAMERON, MOSS, OWEN, 1999; CAMERON, 2001; PEETERS, 2005; FARQUHAR et al., 2006).

\section{A SEGREGAÇÃo DE GÊNERO SE REPRODUZ}

Outra razão que explica a segregação em função do gênero reside no fato de um setor tão dominado por mulheres reproduzir a segregação de gênero através da política, da imagem da profissão, das formações e da seleção, bem como no tipo de profissionalidade construída (ROLFE, 2005). Se quisermos atingir um tipo de profissionalidade neutra no plano do gênero, é então necessário empreender ações a cada um destes níveis.

"Será necessário ainda examinar melhor a forma como os currículos, as organizações e o fomento de formação se comportam como uma força de dissuasão ou de motivação, a fim de responder à questão da exclusão implícita dos homens do setor dos cuidados" (CAMERON; MOSS, 2007, p. 119). 


\section{PARA UMA CONSTRUÇÃO DA PROFISSIONALIDADE NEUTRA DO PLANO DO GÊNERO}

Se quisermos construir uma profissionalidade neutra, do ponto de vista do gênero, no trabalho com crianças, será então necessário redefinir essa construção e separar da ideia de substituição materna (CAMERON; MOSS; OWEN, 1999). Uma profissionalidade que tenha como ponto de partida a substituição da mãe baseada em uma única identidade de gênero, estereotipada e clássica. As identidades de gênero clássicas são construídas com base em diferenças. Partem do princípio que o outro é qualificado como diferente e recorrem, portanto, à exclusão: "Um homem é diferente de uma mulher" (EC CHILDCARE NETWORK, 1993).

Para evitar essa exclusão, é necessário construir um modelo de profissionalidade baseado em uma "multiplicidade de identidades de gênero" (CAMERON; MOSS; OWEN, 1999, p. 20). Michel Vandenbroeck fala de "identidade múltipla" (2005, p. 35): é necessário abandonar uma construção da profissionalidade baseada em uma única identidade (tanto para o gênero como para a cultura ou para a etnia). Existem diferentes pontos de vista, diferentes abordagens, utilizadas por diferentes pessoas, todas elas importantes e, por conseguinte, contestáveis.

É importante que cada definição de profissionalidade seja constantemente posta em causa e que se torne visível através do diálogo e do debate.

\section{CONDIÇÕES PARA UMA PROFISSIONALIDADE NEUTRA NO PLANO DO GÊNERO}

Nesta seção, comparamos os resultados dos estudos do Departamento do Trabalho Socioeducativo e de Políticas Sociais da Universidade de Gand (PEETERS, 2005, VANDENBROECK, PEETERS, 2008; VAN STEENBERGHE, VANRUMST, 2010; SCHANDELER, 2010) aos dados da literatura internacional. Formulamos, a partir daí, algumas condições apropriadas para desenvolver uma profissionalidade neutra do ponto de vista do gênero.

Para poder realizar uma construção da profissionalidade neutra no plano do gênero, o clima das formações e dos serviços deve ser alterado.

Revelando que o acolhimento é marcado pelo "gênero", as instituições que utilizam discursos de gênero poderão considerar um profissional diferente, com um 
trabalho complexo em um modo moderno e precário onde os significados são continuamente negociados entre crianças e adultos e entre adultos. (CAMERON, 2006, p. 77).

A presença de profissionais homens e a participação ativa dos pais nos cuidados de crianças são condições essenciais para alcançar uma construção da profissionalidade neutra no plano do gênero. Certamente, tal profissionalidade só pode desenvolver-se a partir de um espírito crítico e da discussão entre profissionais homens e mulheres, e com os pais e as mães.

Os países escandinavos, que contam com o maior número de homens entre os profissionais da pequena infância, conduziram uma reflexão sobre o assunto, que nos permitiu confirmar que outro tipo de profissionalidade se desenvolve para substituir o papel maternal. Essa profissionalidade caracteriza-se por salários mais elevados e uma abordagem menos centrada nos cuidados: uma abordagem social de antecipação orientada para as atividades externas que permite colocar as crianças em situações "desafiadoras" (PEETERS, 2007; CRIANÇAS DA EUROPA, 2010).

É por isso que é necessário encorajar todas as iniciativas que visam atrair à frente profissionais homens. No entanto, essas não produzirão resultados espetaculares nos próximos anos pela simples razão de que estes profissionais homens qualificados não estão disponíveis no mercado de trabalho (ROLFE, 2005).

É, então, primordial elaborar a formação inicial a partir de uma profissionalidade neutra do ponto de vista do gênero e centrar todas as ações de informação nas formações que conduzem às profissões da pequena infância (VANDENBROECK; PEETERS, 2008).

Os centros de orientação escolar e profissional têm aqui um papel importante a desempenhar. É necessário, principalmente, chamar a atenção dos homens que estão insatisfeitos com as suas funções atuais e que trabalharam com a infância e com a juventude, para as possibilidades oferecidas, por exemplo, pelas formações por contrato de qualificação4 (THOLLON-BEHAR, 2011).

Por outro lado, é conveniente empreender ações para melhor acompanhar os adolescentes do sexo masculino na escolha dos seus estudos. E permitir, ainda, que aqueles que estão interessados em funções relacionadas às crianças pequenas se encontrem com profissionais homens ativos no trabalho com a pequena infância, em

\footnotetext{
${ }^{4}$ Nota da tradutora: contrato de qualificação, hoje chamado Contrato de Profissionalização. Trata-se de um contrato de trabalho em regime de alternância com duração determinada ou indeterminada, com uma ação de profissionalização.
} 
fóruns de emprego, e assim informar sobre as possibilidades criativas de tais funções (ROLFE, 2005; VAN STEENBERGHE; VANRUMST, 2010).

As formações de orientação "para homens" são muito eficazes e permitem atrair a atenção de homens para as formações iniciais (SPENCE, 2007). Graças a essas, o projeto "Men in Childcare", na Escócia, já convenceu 900 homens a seguir uma formação inicial.

As redes de estudantes e profissionais homens, que existem especialmente na Irlanda, na Noruega, na França, na Escócia e na Nova Zelândia, são essenciais porque permitem convencer jovens a iniciar uma formação, ou evitar que aqueles que estão em formação ou que já estão ativos no setor se desvinculem (SCHANDELER, 2010). Essas redes permitem, através dos fóruns na internet, chegar aos estudantes e aos profissionais isolados e fazer dos homens que trabalham com a pequena infância, "atores de mudança" em um processo de alargamento da profissionalidade das profissões da pequena infância (PEETERS, 2010). Além disso, estudos demonstraram que esses fóruns são muito populares entre os utilizadores (MANNAERT, 2006; VANDENHEEDE, 2006).

As formações para funções no âmbito da pequena infância são ministradas em instituições que oferecem formações tanto "tipicamente masculinas" - frequentemente técnicas - como "tipicamente femininas" (VANDENBROECK; PEETERS, 2008, SCHANDELER, 2010). As instituições devem procurar ativamente professores e supervisores homens. É importante que os estudantes homens sejam, de preferência, acompanhados por supervisores de estágio ou orientadores homens.

Um estudo realizado por Michel Vanderbroeck (2008) revelou que a formação "Acolhimento da pequena infância" tem um "currículo oculto". Os instrumentos de ensino utilizados refletem uma profissionalidade "feminina". Um rastreio da neutralidade de gênero destes instrumentos parece necessária para evitar, na medida do possível, esta "tendência de gênero" e para elaborar uma definição neutra dos cursos a este nível.

A profissionalidade nas profissões de acolhimento da pequena infância deve ser alargada. Em países como a Noruega e a Dinamarca, onde a ênfase é colocada nas atividades esportivas e externas, verificamos que se desenvolve uma profissionalidade mais neutra do ponto de vista do gênero e mais atraente para os profissionais homens e para os pais (WOHLGEMUTH, 2003; JENSEN, 2011). Do mesmo modo, uma construção da profissionalidade, na qual a função social de acolhimento da pequena 
infância é muito elaborada (VANDENBROECK, 2005), oferece possibilidades que permitem a participação de mais homens (MELEADY; BROADHEAD, 2002). É neste sentido que os centros Maori que acolhem crianças entre 0 e 6 anos, na Nova Zelândia, são interessantes. Esses centros Kohanga Reo têm o maior número de profissionais masculinos: 30\% dos empregados são homens (PEETERS, 2007, p. 22). Isto explica-se pelo fato de esses centros se considerarem não como serviços da pequena infância, mas como serviços para a família alargada (whànau) e para a comunidade da tribo (iwi) (DALLI, 2006, p. 7).

As estruturas de acolhimento da pequena infância e as escolas devem adaptar a infraestrutura e as condições de trabalho, aos empregados e aos estudantes estagiários homens (sem aventais, trocadores mais altos, banheiros adaptados) (VANDENBROECK; PEETERS, 2008).

Oferecer funções em meio período é claramente um fator motivante para a participação dos homens nas profissões da pequena infância (ROLFE, 2005, PEETERS, 2005). Alguns setores, como o do acolhimento extraescolar, oferecem numerosas funções de meio período. Por outro lado, é possível, além disso, combinar outras funções e ter assim um emprego em tempo integral.

As experiências nos países escandinavos demonstraram que as medidas destinadas a empregar mais homens na pequena infância só são eficazes se forem lançadas a todos os níveis e durante um longo período. A fim de assegurar o equilíbrio entre homens e mulheres, é necessária vontade política para fazer dela uma prioridade durante um período de pelo menos dez anos (MOSS, 2013). Segundo Peter Moss, o apoio do governo a todos os tipos de iniciativas e campanhas é uma condição importante para obter o melhor resultado possível. O governo deve recordar continuamente, nos seus textos políticos, a importância da presença de homens no trabalho com a pequena infância.

\section{REFERÊNCIAS}

BORCHORST, A. The public-private split rearticulated: abolishment of the Danish daddy leave. In: ELLINGSAETER, A.; LEIRA, A (org.). Politicising parenthood in Scandinavia. Bristol: Policy Press, 2006.

CAMERON, C. Promise or problem? A review of literature on men working in the early childhood services. In: Gender, Work and Organisation, n. 8, volume 4, 2001, p. 430-453. 
CAMERON, C. Male workers and professionalism. In: Contemporary Issues in Early Childhood, n. 7, volume 1, 2006, p. 68-79.

CAMERON, C.; MOSS, P. Care Work in Europe. Current understandings and future directions, Londres: Routledge, 2007.

CAMERON, C.; MOSS, P.; OWEN, C. Men in the Nursery: Gender and Caring Work. Londres: Paul Chapman, 1999.

DALLI, C. Being a early childhood teacher: Imagens of professional practice and professional identity during the experience of staring childcare. In: New Zealand Journal of Educational Studies, n. 37, volume 1, 2002, p. 73-85.

DALLI, C. Reflectiong on Professionalism in Early Childhood Education: Views from New Zealand. Presentation at $2^{\text {nd }}$ conference of EC Studies Degrees Network, March, 2006.

DESMET, C. ; PROESMANS, R.; STASSE, I.; VAN MECHELEN, R. Kleine kinderen, grote zorgen. Gent: LEF-Masereel Fonds, 1978.

ENFANTS D’EUROPE, n. 19, 2010.

EUROPEAN COMMISSION CHILDCARE NETWORK. Men as Carers: Report of an International Seminar, Ravenna, mai. 1993, p. 21-22.

EUROPEAN COMMISSION CHILDCARE NETWORK. A Review of Services for Young Children in the European Union 1990-1995. Brussels, EU, 1996.

EUROPEAN COMMISSION. Report on Equality Between Women and Men. Brussels, DG for Employment, Social Affairs and Equal Opportunities, 2006.

FARQUHAR, S.; CABLK, L.; BUCKINGHAM, A.; BUTLER, D.; BALLANTYNE, R. Men at Work: Sexism in Early Childhood Education. Porirua: Childforum Research Network, 2006.

JENSEN, J. Men as worker in childcare services. In: OWEN, C., CAMERON, C. ; MOSS, $P$. (orgs.). Men as Workers in Services for Young Children: Issues of Gender Workforce. Londres: Institute of Education, 1998.

JENSEN, J. The Danish Pedagogue Education. A Case Study, Research Report for European commission, 2011.

MANNAERT, N. Mannen in een gender gesegregeerde zorgopleiding.

Onuitgegeven scriptie: Ugent, 2006.

MELEADY, C.; BROADHEAD, P. Diversity: the norm, not the exception. Children in Europe, 2 (2), 2002, p. 11-15.

MILLER, L. Developing Professionalism in the Early Years. In: 16th Conference de I'EECERA, Reykjavik, 30 août-2 septembre 2005, 2006. 
MOSS, P. Qui est le professionnel de la petite enfance ? Enfants d'Europe, 3 (1), 2003, p. 11-15.

MOSS, P. A New Era for Universal Childcare. Policy Papers, $n^{\circ} 1$, Londres, Day Care Trust, 2004.

OBERHUEMER, P. Conceptualising the early pedagogue policy approaches and issue of professionalism. In: European Early Childhood Education Research Journal, 13 (1), 2005, p. 5-16.

OCDE. The Future of Female Dominated Professions, Paris, 1997.

OCDE. Starting Strong II. Early Childhood Education and Care, Paris, 2006.

PEETERS, J. Mannen in de Kinderopvang: noodzakelijke rolmo delen voor jonge vaders. In: HIG, Vaders in soorte. Tielt: Lannoo, 2002.

PEETERS, J. Men in childcare an action-research in Flanders. International Journal of Equality and Innovation in Early Childhood, 1 (1), 2003, p. 72-83

PEETERS, J. Promoting diversity and equality in early childhood care and educationmen in childcare. In: SCHONFELD, H.; O'BRIEN, S.; WALSH, T. (orgs.). Questions of quality. Dublin: CECDE, 2005.

PEETERS, J. Including men in early childhood education insights from the European experience. In: New Zealand Research in Early Childhood Education, 10, 2007, p. $15-24$.

PEETERS, J. The Construction of a New Profession. A European perspective on professionalism in Early Childhood Education and Care. Amsterdam: SWP Publishers, 2008.

PEETERS, J. Le professionnalisme dans les services aux jeunes enfants en Europe. In: Le Furet, $\mathrm{n}^{\circ} 61,2010$, p. 18-20.

PEETERS, J.; VANDENBROECK, M. Child care practitioners and the process of professionalization. In: MILLER, L.; CABLE; D. (orgs.). Professionalization and Management in the Early Years. Londres: Sage, 2011.

POT, L. Feminisme en kinderopvang. Tegenstrijdige belangen. In: Een organisatie van toevalligheden. Liesbet Pot en dertig jaar kinde ropvang. Utrecht: NIZW. 1981.

ROLFE, H. Men in Childcare. Working Papers, $n^{\circ} 35$, Londres, Equal Opportunities Commission, 2005.

SCHANDELER, V. Les hommes dans les métiers de la petite enfance au Luxembourg. Travail de candidature, Université de Luxembourg, 2010.

SCHÖN, D. Le praticien réflexif. À la recherche du savoir caché dans l'agir professionnel. Montréal: Les Editions Logiques, [1983] 1994. 
SIMPSON, R. Men in non-traditional occupations: Career entry, career orientation and experience of role strain. Gender, Work and Organisation, 12 (4), 2005, p. 363380.

SPENCE, K. Communication au séminaire international "Men in childcare" , 27 avril, ESSSE, Lyon, 2007.

THOLLON-BEHAR, M. P. Les formations en cours d'emploi des éducateurs de jeunes enfants et en apprentissage pour les auxiliaires de puériculture. Case study report, Research Project for European commission, 2011.

VAN STEENBERGHE, T.; VAN RUMST, K. Studiekeuzebegeleiding en beroepsoriëntering naar de opleiding kinderzorg: een genderperpespectief. Universiteit Gent masterproef, 2010.

VANDENBROECK, M. Éduquer nos enfants à la diversité. Toulouse: érès, 2005

VANDENBROECK, M. In Verzekerde bewaring. Amsterdam: SWP, 2009.

VANDENBROECK, M.; PEETERS, J. Gender and professionalism: a critical analysis of overt and covert curricula. In: Early Child Development and Care, 178 (7-8), 2008, p. 703-715.

VANDENHEEDE, E. Gendersegregatie in het onderwijs: jongens in de opleiding "Kinderzorg". Onuitgegeven scriptie: Ugent, 2006.

WOHLGEMUTH, U. Les hommes dans les cours pour les pédagogues. In: Enfants d'Europe, 3(5), 2003, p. 22-23.

\section{NOTAS}

PROFISSIONALIDADE E GÊNERO: PARTICIPAÇÃO DOS HOMENS E PEQUENA INFÂNCIA Professionalité et genre: participation des hommes et petite enfance Professionality and gender: men's participation and early childhood

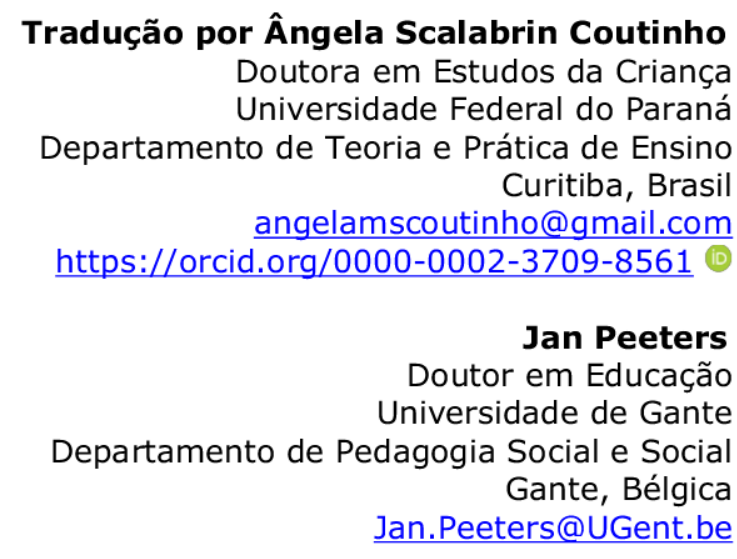


Endereço de correspondência do principal autor

Jan Peeters. Henri Dunantlaan 29000 Gent - België

\section{AGRADECIMENTOS}

$-$

CONTRIBUIÇÃO DE AUTORIA

Concepção e elaboração do manuscrito: J. Peeters

Coleta de dados: J. Peeters

Análise de dados: $\mathrm{J}$. Peeters

Discussão dos resultados: J. Peeters

Tradução: A. S. Coutinho

Revisão e aprovação: A. S. Coutinho

\section{CONJUNTO DE DADOS DE PESQUISA}

O conjunto de dados que dá suporte aos resultados deste estudo não está disponível publicamente.

\section{FINANCIAMENTO}

Não se aplica.

LICENÇA DE USO - uso exclusivo da revista

Os autores cedem à Zero-a-Seis os direitos exclusivos de primeira publicação, com o trabalho simultaneamente licenciado sob a Licença Creative Commons Attribution (CC BY) 4.0 International. Esta licença permite que terceiros remixem, adaptem e criem a partir do trabalho publicado, atribuindo o devido crédito de autoria e publicação inicial neste periódico. Os autores têm autorização para assumir contratos adicionais separadamente, para distribuição não exclusiva da versão do trabalho publicada neste periódico (ex.: publicar em repositório institucional, em site pessoal, publicar uma tradução, ou como capítulo de livro), com reconhecimento de autoria e publicação inicial neste periódico.

PUBLISHER - uso exclusivo da revista

Universidade Federal de Santa Catarina. Núcleo de Estudos e Pesquisas da Educação na Pequena Infância - NUPEIN/CED/UFSC. Publicação no Portal de Periódicos UFSC. As ideias expressadas neste artigo são de responsabilidade de seus autores, não representando, necessariamente, a opinião dos editores ou da universidade.

EDITORES - uso exclusivo da revista Márcia Buss-Simão e Kátia Agostinho.

HISTÓRICO - uso exclusivo da revista

Recebido em: 23-09-2020 - Aprovado em: 02-10-2020 